\title{
REFORMAS EDUCATIVAS E OPINIÕES DOS PROFESSORES SOBRE O INSUCESSO EM FÍSICA E QUÍMICA
}

\author{
EDUCATIONAL REFORMS AND TEACHERS' OPINIONS \\ ON FAILURE IN PHYSICS AND CHEMISTRY
}

\section{REFORMAS EDUCATIVAS Y OPINIONES DE LOS MAESTROS SOBRE EL FRACASO EN FÍSICA Y QUÍMICA}

\author{
Cesarina Augusto \\ José Paulo Cravino ${ }^{\mathrm{I}}$ \\ Armando A. SoARES ${ }^{\mathrm{I}}$ \\ . BERNARDINO LOPES ${ }^{\mathrm{I}}$
}

Resumo Este estudo baseia-se numa análise documental da opinião dos professores quanto às possíveis causas para o insucesso na disciplina de Física e Química no ensino secundário nos últimos 80 anos, em Portugal. Os resultados da pesquisa apontam, entre outras, duas causas: programas extensos e número elevado de alunos por turma. Apesar de durante esse período terem sido implementadas várias reformas do sistema educativo, com o objetivo de melhorar as aprendizagens dos alunos nessa disciplina, verifica-se a persistência das percepções dos professores quanto às causas do insucesso. Discutem-se possíveis razões para esses resultados.

Palavras-chave: Ensino de Física e Química; Insucesso; Percepções dos professores.

ABstract This study is based on a documentary analysis of teachers' opinion about the possible causes for the failure in the discipline of Physics and Chemistry in secondary education over the last 80 years, in Portugal. The results indicate, among others, two causes: long lists of contents to teach and large number of students per class. Despite of the implementation of-several reforms in the education system, in order to improve student learning

Universidade de Trás-os-Montes e Alto Douro (UTAD), Vila Real - Portugal. 
in this discipline, the perceptions of teachers about the causes of failure persist unchanged. Possible reasons for these results are discussed.

Key-words: Physics and Chemistry Teaching; Failure; Perceptions of teachers.

RESumen Este estudio se basa en un análisis documental de la opinión de los profesores sobre las posibles causas del fracaso en la disciplina de Física y Química en la enseñanza secundaria en los últimos 80 años, en Portugal. Los resultados del estudio indican, entre otros, dos causas: extensos programas y gran número de estudiantes por clase. A pesar de durante este tiempo se han aplicado varias reformas del sistema educativo, con el fin de mejorar el aprendizaje de los estudiantes en esta disciplina, las percepciones de los profesores sobre las causas del fracaso parecen persistir. Se discuten posibles razones de estos resultados.

Palabras clave: Enseñanza de Física y Química; Fracaso; Percepciones de los maestros.

\section{INTRODUÇ̃̃o}

As reformas curriculares em Portugal, até 1980, centravam-se na aquisição de conteúdos, com o objetivo de familiarizar os alunos com teorias, conceitos e processos científicos. Depois de 1980, essas preocupações foram alteradas, tendo o currículo passado a dar mais importância ao objetivo de formar cidadãos conscientes e capazes de tomar decisões sobre assuntos relacionados com a Ciência, Tecnologia e Sociedade (CTS).

Os programas foram sofrendo alterações significativas, ao longo dos anos, que passaram principalmente pela retirada de certos conteúdos e pela introdução de novos, tendo muitas vezes o objetivo declarado de simplificar, por forma a obter melhores resultados nos exames (por exemplo, Decreto-Lei n ${ }^{\circ} .37112$ de 1948). Apesar das constantes alterações aos programas, o objetivo de se alcançar melhores resultados não foi concretizado (AUGUSTO, 2014).

Com este estudo pretendemos, recorrendo a uma análise de conteúdo de documentos, dar a conhecer a opinião dos professores sobre as causas do insucesso na disciplina de Física e Química, no ensino secundário em Portugal entre 1936 e 2013. As opiniões dos professores centram-se na extensão dos programas e no número de alunos por turma como causas principais do insucesso. Essas opiniões foram cruzadas com a análise realizada à legislação em vigor, nomeadamente ao longo desse período.

Os resultados dos exames nacionais foram considerados um indicador das aprendizagens dos alunos. Assim, foi realizada uma análise aos resultados dos exames nos anos que se seguiram à implementação dos novos programas da disciplina de Física e Química. O objetivo foi verificar se, após as novas reformas, os resultados dos exames melhoraram.

O problema de investigação consiste em refletir o que leva várias gerações de professores, ao longo de cerca de 80 anos, a atribuírem como causas prováveis para o insucesso na disciplina de Física e Química no ensino secundário a extensão dos programas e o número elevado de alunos por turma, apesar das diferentes reformas implementadas no sistema educativo, ao longo dos anos.

70 Comunicações | Piracicaba | v. 24 | 1.1 | p. 69-82 |janeiro-abril 2017 
O organismo governamental responsável pela educação em Portugal é o Ministério da Educação, que tem entre outras a função de "definir, coordenar, promover, executar e avaliar as políticas nacionais dirigidas aos sistemas educativo e científico e tecnológico, articulando-as com as políticas de qualificação e formação profissional" (artigo $1^{\circ}$. do Decreto-lei $n^{\circ}$. 25/2011, p. 5.499). No mesmo artigo, na alínea h, pode ler-se "Definir o currículo nacional e o regime de avaliação dos alunos e aprovar os programas de ensino e as orientações para a sua concretização".

O decreto número 37:112, de 22 de (outubro de 1948, p. 1.082), refere: "surgiu a necessidade de remodelar os programas do mesmo ensino, adaptando-os ao novo plano de estudos por meio de correções e simplificações aconselhadas pela prática da função docente". Esse pequeno texto mostra que as alterações dos programas tiveram em consideração as opiniões dos professores.

Coloca-se assim a questão: a percepção dos professores quanto aos programas extensos e número elevado de alunos por turma é justificativa do insucesso escolar?

Para obter as respostas a essa questão, interessa perceber como são definidos os programas pelo Ministério da Educação.

Segundo Ferreira (2010), programa é um conjunto de conteúdos e aprendizagens com determinada finalidade. Ainda de acordo com o mesmo autor "os professores confrontam-se com a necessidade de gerir um currículo formal que é definido por equipas ministeriais e uniforme a nível nacional" (FERREIRA, 2010, p. 48).

O programa elaborado no Ministério da Educação é aquele que deve ser aplicado em sala de aula. No entanto, é ao professor que cabe a função de gerir os conteúdos desse programa.

Assim, a definição de programa extenso apresenta-se de difícil clarificação, dada a relatividade do conceito em consequência da interpretação que cada professor pode dar às orientações para o ensino da Física e Química, ao grau de dificuldade que atribui a cada tema a lecionar e ainda a forma como o professor gere o tempo para lecionar os conteúdos. Esses três aspectos podem ser a diferença entre a percepção de um programa extenso e o que está efetivamente no documento.

No programa de Física e Química, homologado em 2003 para o $11^{\circ}$. Ano, era mencionado o seguinte para a componente da Química.

No caso do $11 .^{\circ}$ ano, prevêem-se no total 49 aulas (90 minutos cada), das quais 16 para a Unidade 1 (incluindo 3 aulas para a visita a uma indústria) e 27 para a Unidade 2. As restantes (6 aulas) ficarão para gestão pelo professor, de acordo com as características da turma" (MARTINS, et al., 2003, p. 3).

Para a componente de Física "das 49 aulas previstas para a componente de Física, fez-se uma programação apenas para 36, de modo a que o professor possa gerir as 13 aulas restantes de acordo com as necessidades dos alunos e eventuais condicionamentos (BELLO, et al., 2003, p. 57).

Nesse programa já estavam contempladas aulas destinadas a serem geridas autonomamente pelos professores, o que não acontecia nos programas entre 1936 e 1974, em que 
a gestão era feita inteiramente pelos professores. Segundo Ferreira (2010), a gestão dos conteúdos dos programas é realizada pelos professores. A dinâmica dada na abordagem dos mesmos em sala de aula pode não ser a mais adequada para o cumprimento do programa e pode levar à percepção de que os programas são extensos.

Por sua vez, a falta de tempo para lecionar os conteúdos foi sempre uma preocupação manifestada pelos professores. Principalmente no componente experimental, pelo fato da execução das experiências indicadas no programa serem demoradas na sua realização (e.g. COSTA, 1953).

Note-se que, em 2003, passam a existir aulas de caráter prático experimental com a duração de 135 minutos.

Outro aspecto apontado para o insucesso na disciplina, segundo os professores, é o elevado número de alunos por turma, ou seja, quanto maior o número de alunos por turma tanto maior a dificuldade nas aprendizagens dos alunos. No entanto, o número de alunos por turma diminuiu no período de 1999 a 2000, depois voltou a aumentar, mas ficando sempre com valores inferiores a 1964.

$\mathrm{O}$ que se constata através de estudos internacionais e nacionais é que não existem evidências de que uma turma com um número reduzido de alunos seja necessariamente sinônimo de melhores resultados.

Passo a citar parágrafos de alguns desses estudos.

Gomes (2005, p. 286) refere: "Quanto ao tamanho da turma, Waiselfisz (2000a, 2000b) confirmou em linhas gerais a literatura internacional: não foram encontradas evidências de que, quanto menor a turma, maior o seu aproveitamento".

Também:

É imperioso que o professor mobilize os alunos, os faça levantar questões, os motive, comunique com eles, os ensine a comunicar com os colegas de turma, faça da sala de aula um lugar de experiências inolvidáveis, que lhes permita crescerem, tudo isto independentemente de estar perante uma turma de vinte alunos ou perante uma turma reduzida como é o nosso caso (CANÁRIO, 2013, p. 123).

Ao fazê-lo, basearam-se num conjunto considerável de estudos e evidências experimentais sobre os impactos das turmas mais reduzidas no desempenho escolar dos alunos. Uma revisão completa da literatura está fora do âmbito deste documento, mas, a título de resumo simples, pode dizer-se que os resultados são mistos, com algum benefício nos primeiros anos de escolaridade, mas que não se mantém ao longo da vida académica do aluno... (RAYMOND M. \& NEGOSSI Y., 2015, p. 41).

Segundo esses autores, e como já referido, não há evidências significativas quanto à melhoria das aprendizagens dos alunos, devido apenas ao fato de as turmas terem ou não um número reduzido de alunos.

Este estudo é pertinente pelo fato de que ao longo dos anos houve mudanças, quer na sociedade, quer no sistema educativo, e, no entanto, a maioria dos professores conti- 
nua a ter as mesmas opiniões. Por isso, o interesse em saber qual o motivo pelo qual isso acontece. Deverá haver uma causa, seja ela externa ou interna, que leva os professores a manterem a opinião.

\section{Metodologia}

Este estudo está dividido em dois períodos: 1936 a 1974 e 1999 a 2013. Os anos entre 1975 e 1999 não são referidos porque não foi possível obter os elementos necessários para a sua análise.

A metodologia utilizada foi a análise documental, segundo Bardin (2011, p. 47), que define a análise documental "uma operação ou conjunto de operações visando representar o conteúdo do documento sob a forma diferente do original, a fim de facilitar num estudo ulterior a sua consulta e referenciação". A estratégia de análise consistiu em fazer a análise de conteúdos das seguintes fontes de dados:

I) Relatórios de avaliação de cada professor que eram enviados à Inspeção Geral do Ensino Liceal (112 relatórios entre 1934 e 1962) com o intuito de retirar informações sobre as suas práticas letivas e opiniões sobre os programas, número máximo de alunos por turma e horas de aulas por semana;

II) Decretos lei dos Diários da República (de 1936, 1947, 1954 e 2001) para analisar: os programas, número máximo de alunos por turma e eventuais orientações metodológicas;

III) Estatística do Ministério da Educação e do Instituto Nacional de Estatística para obter os resultados dos exames nacionais da disciplina de Física e Química;

IV) Livro Branco da Física e Química, para obter informação sobre os aspectos já referidos em i);

V) Um inquérito do tipo questionário realizado para 30 professores de Física e Química durante um encontro de professores da disciplina em 2013.

Duas das questões colocadas no inquérito realizado foram as seguintes: "Relativamente aos programas que lecionou, dê a sua opinião sobre os programas das disciplinas de Ciências Física Química, Física e Química A e Física e Química" e "Com base na sua prática letiva, indique três aspectos/fatos que na sua opinião podem explicar o elevado insucesso escolar e a desmotivação dos alunos na disciplina de Física e Química”. As informações recolhidas por análise de conteúdo dos documentos das diferentes fontes de dados foram sistematizadas e cruzadas para complementar e conferir maior fiabilidade aos resultados.

\section{Resultados}

Quanto aos programas de Física e Química A, é essencial que estes conduzam à formação de alunos com capacidade de autonomia, de resolução de situações novas, que aparecem no seu quotidiano e com bases seguras para o prosseguimento de estudos. Para isso, é necessário que o programa esteja em consonância com o tempo atribuído para o objetivo a atingir. 
Da análise dos programas, verifica-se que estes sofreram alterações nos conteúdos programáticos ao longo dos tempos. Torna-se difícil definir programas extensos, quando as próprias opiniões dos professores divergem, a maioria refere que são extensos, contudo existem professores que não os consideram extensos. Esse fato é constatado da análise feita às respostas dadas por 26 professores ao questionário realizado em 2013, em que a maioria dos professores respondentes, $73,1 \%$ (19 professores), dizia que os programas eram extensos e $26,9 \%$ (sete professores) consideraram os programas adequados.

Aqui outra questão se coloca: qual a razão dessa discordância entre pares?

Num estudo feito por Ferreira (2006) ao programa do secundário referente à unidade 1.1 do programa do $10^{\circ}$. ano homologado em 2003, pode ler-se:

As sugestões de metodologias para as atividades em sala de aula nem sempre
são bem conseguidas. Se não vejamos:
Na primeira parte da unidade - Arquitetura do Universo - são referidas algumas
sugestões metodológicas de fácil aplicabilidade, sendo, contudo, por vezes di-
fícil, por exemplo, o acesso por parte da maioria dos alunos à Internet. É óbvio
que os alunos podem fazê-lo na escola, mas nem sempre se consegue otimizar
os tempos letivos, com as disponibilidades das escolas em termos informáticos.
Sendo assim, aquilo que aparentemente se poderia lecionar num determinado
número de aulas, é normalmente lecionado num número superior, pois as es-
colas não têm as condições previstas para a execução do programa tal como
está programado. Esta dificuldade começa desde logo a introduzir um atraso no
cumprimento do programa... (FERREIRA, 2006, p. 34).

Mais à frente pode ler-se: "Os professores consideram de um modo geral, que um possível insucesso não se trata de uma questão de conteúdos mas sim numa indefinição de conteúdos..." (FERREIRA, 2006, p. 71).

Segundo esses exertos, depreende-se que a dificuldade de lecionar os conteúdos não está nos conteúdos, mas sim na falta de clarificação dos programas quanto ao grau de complexidade a atribuir aos temas a abordar.

E quando se dão sugestões de difícil execução pelas condições existentes na escola, não é fácil cumprir o que é proposto pelo programa.

Na Tabela 1, mostram-se os temas e subtemas dos conteúdos programáticos dos anos 1948 e 2001. Das reformas realizadas desde 1936 até hoje escolheu-se a reforma de 1948 pelo fato de os anos complementares terem passado a ser constituídos por dois anos, $6^{\circ}$. e $7^{\circ}$. ano (correspondentes ao $10^{\circ}$. e $11^{\circ}$. atuais), e escolheu-se o programa de 2003 do $11^{\circ}$. ano por ser o programa que terminou no ano de 2016. 
Tabela 1. Conteúdos programáticos dos programas de Física e Química de 1948 e 2003.

\begin{tabular}{|c|c|}
\hline $\begin{array}{l}\text { Programa de FÍSICA } \\
\text { E QUÍMICA } 1948\end{array}$ & Programa de FÍSICA E QUÍMICA 2003 \\
\hline $7^{\circ}$. Ano Física & $11^{\circ}$. Ano Física \\
\hline $\begin{array}{l}\text { Termodinâmica - Objeto de ensino - } \\
14 \text { itens }\end{array}$ & 1.1 Viagens com GPS - Objeto de ensino - 5 itens \\
\hline Ótica - Objeto de ensino - 46 itens & 1.2 Da Terra à Lua - Objeto de ensino - 11 itens \\
\hline $\begin{array}{l}\text { Eletricidade - Objeto de ensino - } 23 \\
\text { itens }\end{array}$ & Unidade 2 - Comunicações \\
\hline $\begin{array}{l}\text { Corrente elétrica - Objeto de ensino } \\
-19 \text { itens }\end{array}$ & $\begin{array}{l}\text { 2.1 Comunicação de informação a curta distância - } \\
\text { Objeto de ensino - } 15 \text { itens }\end{array}$ \\
\hline $\begin{array}{l}\text { Magnetismo - Objeto de ensino - } 59 \\
\text { itens }\end{array}$ & $\begin{array}{l}\text { 2.2 Comunicação de informação a curta distância - } \\
\text { Objeto de ensino - } 5 \text { itens }\end{array}$ \\
\hline 11 Atividades laboratoriais & 7 Atividades Laboratoriais \\
\hline 7. Ano Química & $11^{\circ}$. Química \\
\hline $\begin{array}{l}\text { Teoria Iónica - Objeto de ensino - } 67 \\
\text { itens }\end{array}$ & $\begin{array}{l}\text { Unidade } 1 \text { - Química e Indústria: Equilíbrios e de- } \\
\text { sequilíbrios }\end{array}$ \\
\hline $\begin{array}{l}\text { Química Orgânica - Objeto de ensino } \\
-5 \text { itens }\end{array}$ & $\begin{array}{l}1.1 \text { O amoníaco como matéria-prima - Objeto de } \\
\text { ensino - } 7 \text { itens }\end{array}$ \\
\hline $\begin{array}{l}\text { Compostos Alifáticos - Objeto de } \\
\text { ensino - } 109 \text { itens }\end{array}$ & $\begin{array}{l}\text { 1.2 O amoníaco, a saúde e o ambiente - Objeto de } \\
\text { ensino } 2 \text { itens }\end{array}$ \\
\hline \multirow[t]{7}{*}{$\begin{array}{l}\text { Compostos Aromáticos - Objeto de } \\
\text { ensino - } 13 \text { itens }\end{array}$} & $\begin{array}{l}\text { 1.3 Síntese do amoníaco e Balanço Energético } \\
\text { Objeto de ensino - } 2 \text { itens }\end{array}$ \\
\hline & 1.4 Produção Industrial do amoníaco \\
\hline & Objeto de ensino - 10 itens \\
\hline & 1.5 Controle da produção Industrial \\
\hline & $\begin{array}{l}\text { Unidade } 2 \text { - Da Atmosfera ao Oceano: Soluções na } \\
\text { Terra e para a Terra }\end{array}$ \\
\hline & $\begin{array}{l}\text { 2.1 Água da chuva, água destilada e água pura - } \\
\text { Objeto de ensino - } 10 \text { itens }\end{array}$ \\
\hline & $\begin{array}{l}\text { 2.2 Águas minerais e abastecimento público, a aci- } \\
\text { dez e a basicidade das águas - Objeto de ensino - } 10 \\
\text { itens }\end{array}$ \\
\hline $\begin{array}{l}13 \text { Trabalhos Práticos (atividades } \\
\text { laboratoriais) }\end{array}$ & 9 Atividades Laboratoriais \\
\hline
\end{tabular}

A Tabela 1 foi elaborada a partir do programa instaurado em 1948, aprovado no decreto número 37:112, de 22 de outubro de 1948, e do programa de $11^{\circ}$. Ano, implementado em março de 2003.

Comparando os temas e subtemas que os dois programas continham, constatou-se que os conteúdos dos itens que os alunos deviam aprender são em maior número no programa 
de 1948 do que no programa implementado em 2003. O que podemos depreender desse fato é que, embora a extensão dos conceitos a lecionar tenha diminuído, os professores continuam a ter a percepção que os programas são extensos. A explicação possível para essa constatação por parte dos professores deve-se ao fato de verificarem que os seus alunos não apreenderam os conhecimentos que eram propostos, e isso leva a que os professores tenham a opinião que os programas são extensos. Refletindo nesse aspecto, pode-se dizer que talvez a quantidade de conteúdos a apreender, para uma aprendizagem eficaz, não esteja em concordância com o tempo atribuído ao ensino da mesma.

No que diz respeito ao aspecto do número elevado de alunos por turma, este também tem sofrido algumas alterações:

Entre 1936 até 1974 as turmas eram maiores do que as atuais. Nos anos em causa a indisciplina existente em sala de aula era insignificante, mas atualmente a indisciplina está patente e contribui para o insucesso nas aprendizagens. Por sua vez, parece que não é propriamente o número de alunos por turma a causa dos fracos resultados dos alunos, pois atualmente o número de alunos é menor, mas em contrapartida a indisciplina é maior.

Figura 1. Representação do número de alunos por turma (máximo a azul e mínimo a vermelho) no $6^{\circ}$. e $7^{\circ}$. ano $\left(10^{\circ}\right.$. e $11^{\circ}$. ano $)$ em diferentes períodos do intervalo de tempo analisado.

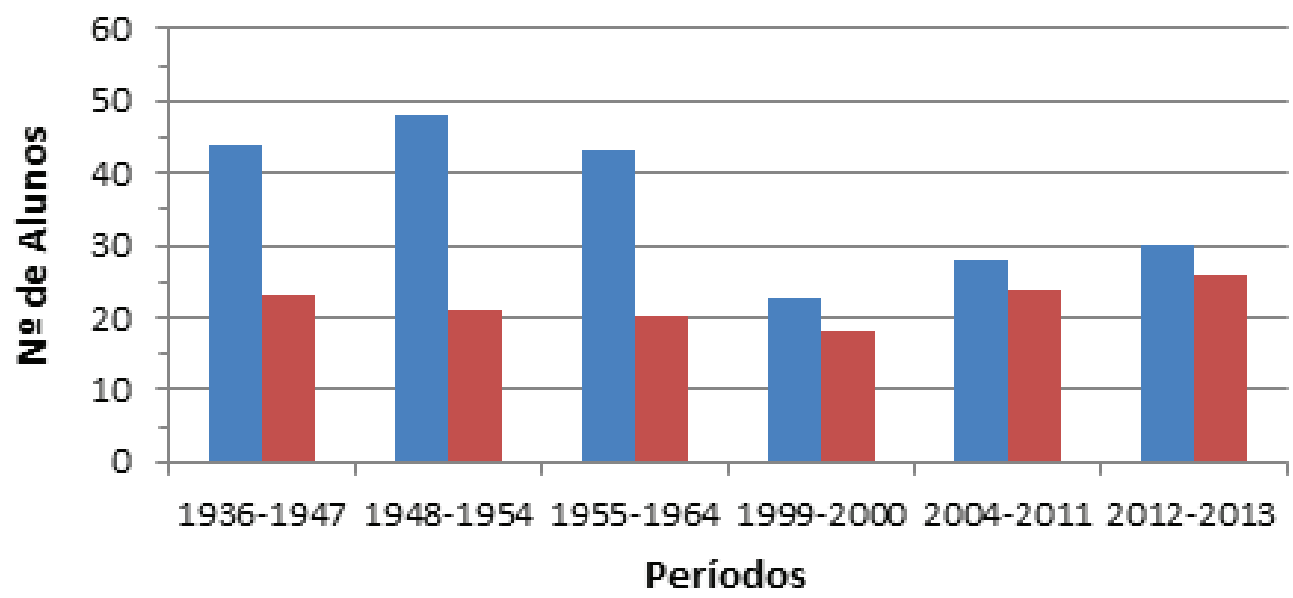

A Figura 1 foi elaborada a partir dos dados fornecidos pelos relatórios dos professores e legislação.

Como se pode verificar, o número máximo de alunos por turma sofreu oscilações ao longo dos períodos mencionados.

No período entre 1948 e 1954, verificou-se maior aumento do número máximo de alunos por turma, onde as turmas eram compostas em média por 45 alunos. Entre 1936 e 1947, bem como, entre 1955 e 1964, o número de alunos por turma era aproximadamente de 42-43 alunos (AUGUSTO, 2014). 
No ano letivo 1999/2000, a média do número máximo de alunos no $10^{\circ}$. e $11^{\circ}$. ano por turma referido no livro Branco de Física e Química era de 23 alunos e o mínimo de 18 alunos. Devido ao fato de nesse período os alunos desses anos não terem exame de Ciências Física Química (CFQ), não é possível verificar se esses alunos tiveram ou não melhores resultados relativamente a alunos inseridos em turmas com maior número de alunos. Em 2004, o número estipulado pelo Ministério da Educação no Despacho 13:765/2004 (de 13 de julho de 2004, p. 18 807), foi de 28 alunos no máximo e 24 no mínimo, em 2012 com o Despacho ${ }^{\circ} .510$ G-A/2012 (de 12 abril, p. 13.270-[5]) o número máximo passa a 30 e o mínimo a 28 alunos.

Com os dados recolhidos não é possível identificar uma relação causa-efeito entre turmas pequenas e melhores resultados. Para essa identificação, era necessário fazer outro tipo de estudo, tentando controlar o máximo de variáveis possíveis para averiguar o efeito do número de alunos por turma (AUGUSTO, 2014).

Para compreender se a extensão dos programas, bem como, o número elevado de alunos por turma foi relevante para os resultados obtidos pelos alunos nos exames nacionais construíram-se dois gráficos: um para mostrar as percentagens de classificações dos anos referidos e outro onde está representada a média nacional nos exames entre 2006 e 2013, dos alunos externos e internos. Faz-se ainda uma pequena análise dos resultados obtidos.

Figura 2. Distribuição das classificações positivas e negativas dos exames nacionais realizados entre 1941 e 1967.

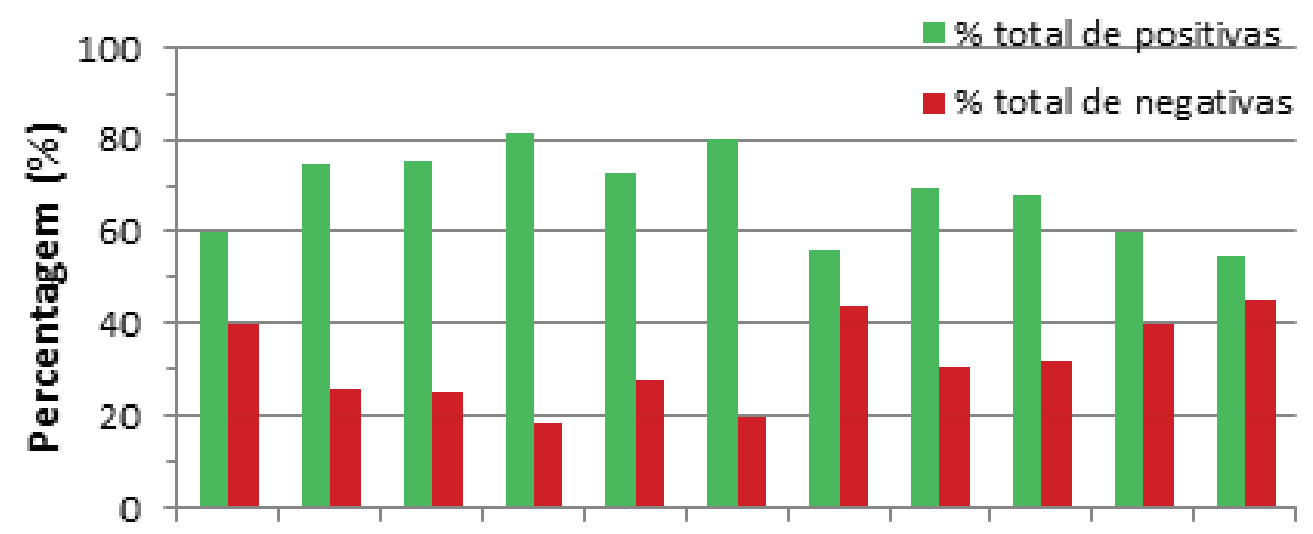

19411946194719481950195119521953195519571967

Anos

A Figura 2 foi elaborada a partir de dados recolhidos nos livros do Instituto de Estatísticas de educação dos exames nacionais.

Pelo fato de não se ter conseguido obter a classificação de cada um dos alunos em todos os anos referidos, não foi possível calcular a média nacional do exame da disciplina de CFQ. 
Da Figura 2 podemos verificar que entre 1941 e 1948 a percentagem de classificações negativas foi entre $40 \%$ e 19\%. Após a reforma do ensino Liceal em 1948, altura em que os programas sofreram alterações nos conteúdos programáticos, verifica-se que a percentagem de classificações negativas ultrapassa os $20 \%$, voltando a ter um aumento no ano de 1952, quando ultrapassa os 40\%. Esse programa só entrou em vigor no exame de 1949. Constata-se da Figura 2 que, em 1950, um ano após a implementação do novo programa, a percentagem de classificações negativas aumentou. Assim, a estratégia de melhorar os resultados com a implementação de reformas nos conteúdos parece ineficaz.

Há um fator importante que não pode deixar de ser referido, os exames têm graus de dificuldade diferentes de ano para ano, no entanto esse grau de dificuldades pode estar relacionado com os conteúdos lecionados.

Na Figura 3 estão representados os resultados dos exames nacionais a partir de 2006, altura do início do exame nacional de Física e Química no $11^{\circ}$. ano. E, desde então, tem-se mantido até os nossos dias, durante esse período não existiram alterações nos conteúdos programáticos. A última reforma dos programas entrou em vigor em 2003 e terminou em 2015 para o $10^{\circ}$. ano e 2016 para o $11^{\circ}$. ano.

Figura 3. Distribuição em percentagem de classificações positivas e negativas obtidas nos exames nacionais entre 2006 e 2013.

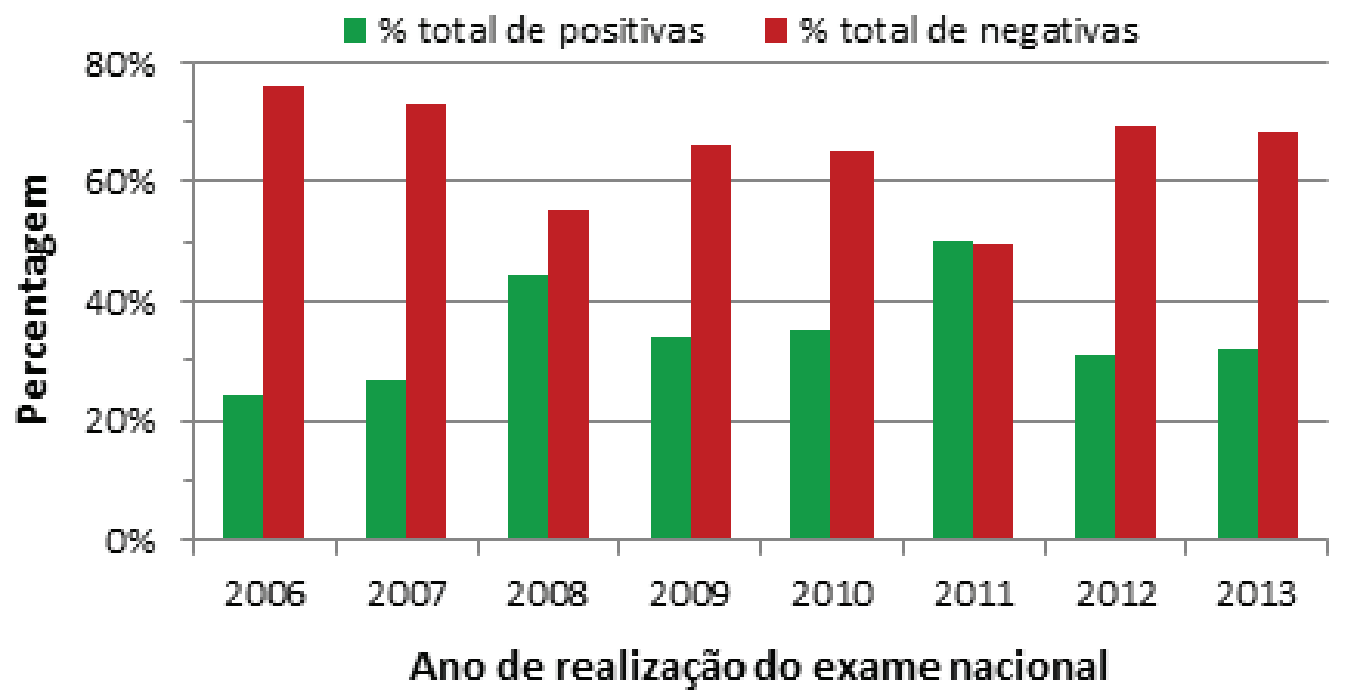

A Figura 3 foi elaborada a partir dos dados do Júri Nacional de Exames (JNE) e do IAVE (disponíveis em www.dgidc.min-edu.pt/jurinacionalexames/index. php? $\mathrm{s}=$ diretorio\&pid $=4$ ).

Da análise feita à Figura 3 verifica-se que só em 2011 é que a percentagem de positivas e negativas foi praticamente a mesma. No período analisado na Figura 3, o programa não sofreu alterações e apesar disso, os resultados dos exames têm sido desastrosos (com taxas de reprovações sistematicamente superiores a 50\%). Como se pode verificar, mais uma vez os resultados não mostram melhorias significativas ao longo dos anos. Isso po- 
derá dar a entender que as alterações nos programas e no número de alunos por turma não podem ser correlacionadas, pelo menos de um modo direto, com as classificações de exame obtidas pelos alunos. Assim, devem ser tidos em conta outros aspectos, como aumentar o número de tempos semanais e ter em conta as características dos alunos na constituição das turmas (AUGUSTO, 2014).

As classificações dos exames nacionais mostram que as alterações feitas aos programas não têm atingido os objetivos pretendidos. De fato, da análise dos resultados verifica-se que há anos melhores que outros, mas esse fato pode estar relacionado com outros fatores, por exemplo, o grau de exigência das provas de exame e diferenças nos critérios de correção.

\section{CONSIDERAÇões FINAIS}

Do estudo realizado, conclui-se que existem duas opiniões distintas acerca do mesmo assunto. Uma parte significativa dos professores $(73,1 \%)$ diz que os programas são extensos, contudo existe um grupo mais reduzido $(26,9 \%)$ que tem opinião contrária, pelo que deve haver alguma causa que interfere nessa percepção. Uma provável causa pode estar relacionada com o ritmo imposto em sala de aula e com as características das turmas. Sendo o professor o gestor dos programas, terá que os organizar em conformidade com as suas turmas.

Os objetivos dos programas podem estar corretos, mas a sua implementação e concretização podem não estar em sintonia com o tempo letivo atribuído à disciplina para uma aprendizagem eficaz. Falar em programas extensos quando nos referimos aos conteúdos dos programas parece não ser consensual. A percepção da extensão dos programas é diferente do que está nos mesmos. Essa percepção do professor pode ter várias origens, como a dinâmica em sala de aula na lecionação dos conteúdos não ser a mais adequada, as características da turma e o tempo atribuído a cada um dos temas de modo a serem atingidos os objetivos/finalidades nomeados nos programas.

Quanto ao número de alunos por turma, os estudos mostram que as aprendizagens dos alunos não melhoram necessariamente apenas pela redução do número de alunos por turma. No entanto, há que referir que esses valores variaram ao longo de todo esse tempo, o que não pode ser dissociado das aprendizagens dos alunos.

Dos resultados dos exames nacionais depreendemos que, mesmo quando os conteúdos programáticos e o número de alunos por turma são alterados, os resultados não mostram melhorias significativas. Apesar de todas as alterações realizadas no sistema educativo nos últimos anos, verifica-se que a média dos resultados dos exames nacionais desde 2006 a 2013 tem mantido valores negativos à exceção do ano 2011.

\section{REFERÊNCIAS}

AUGUSTO, C. Conteúdos Programáticos de Física e de Química no Ensino Secundário e Implicações no Insucesso Escolar, 2014, 119s. Dissertação (Mestrado em Ensino de Física e de Química no $3^{\circ}$. Ciclo do Ensino Básico e no Ensino Secundário), Universidade de Trás-os-Montes e Alto Douro, Vila Real. 
BARDIN, L. Análise de conteúdo. Tradução L. A. Reto \& A. Pinheiro. São Paulo: Edições 70, 2011.

BELLO, A. et al. Programa de Física e Química do 11 $^{\circ}$ ano. Ministério da Educação Departamento do Ensino Secundário. Lisboa, 2003, p. 97.

CANÁRIO, L. F. P. Métodos e Técnicas e Recursos Didáticos aplicados numa turma reduzida do 11 $^{\circ}$. ano de Economia do ensino secundário, 2013. Dissertação (Mestrado em Ensino de Economia e Contabilidade). Universidade de Lisboa, Lisboa.

COSTA, J. Relatório para a inspeção do ensino liceal, 1953. Arquivo Histórico do Ministério da Educação, caixa $n^{\circ} .12$, relatório $n^{\circ}$. 618. Lisboa.

FERREIRA, I. L. Os professores e o Currículo: Perceção e Níveis de Intervenção dos professores do Ensino Básico no Desenvolvimento curricular. 2010. Dissertação (Mestrado em Supervisão Pedagógica), Universidade Aberta. Lisboa. Disponível em: https://repositorioaberto.uab.pt/bitstream/10400.2/1728/1/Dissertac...pdf. Acesso em: 26 jul. 2016.

FERREIRA, M. J. O. Análise curricular de Física e Química do Ensino Secundário, 2006. Dissertação de Mestrado no Ensino da física e da Química, Universidade de Coimbra, Coimbra.

GOMES, C. A. (2005). A Escola de Qualidade para Todos: Abrindo as Camadas da Cebola. Ensaio: Avaliação e Políticas Públicas em Educação, 13 (48), 281-306. Disponível em: http://www.scielo.br/pdf/ensaio/v13n48/27551.pdfacesso . Acesso em: 28 jun. 2016.

Instituto de Avaliação Educativa I.P (IAVE): relatórios sobre os resultados dos exames nacionais. Lisboa. Disponível em http://iave.pt/np4/documentos?tema=8 Acesso em: 22 set. 2016.

Instituto Nacional de Estatística (1945 a 1957). Estatísticas do Ensino. Biblioteca Nacional. Juri Nacional de Exames JNE: resultados dos exames nacionais, estatísticas. Lisboa. Disponível em http://www.dge.mec.pt/estatisticas. Acesso em: 22 set. 2016.

Juri Nacional de Exames JNE: relatórios dos exames nacionais, estatísticas. Lisboa. Disponível em http://www.dge.mec.pt/relatórios. Acesso em: 22 set. 2016.

MARTINS, A. et al. Livro Branco da Física e da Química. Sociedade Portuguesa da Física e Sociedade Portuguesa da Química. Lisboa, 2002, 200p.

MARTINS, J. P. et al. Programa de Física e Química do $1^{\circ}$. ano. Ministério da Educação Departamento do Ensino Secundário. Lisboa, 2003, 97p.

PORTUGAL, LISBOA. Decreto-lei nº 37 112, de 22 de outubro de 1948: Aprova os programas das disciplinas do ensino liceal. Diário do Governo, 1948.

PORTUGAL, LISBOA. Decreto n ${ }^{\circ} .27$ 084, de 14 de outubro de 1936: Promulga a reforma do ensino liceal. Diário do Governo, 1936.

80 Comunicações | Piracicaba | v. 24 | $\mid$ n. 1 | p. 69-82 |janeiro-abril 2017 
PORTUGAL, LISBOA. Decreto $n^{\circ} .27$ 085, de 14 de outubro de 1936: Aprova para vigorarem a partir do ano letivo 1936/37, os programas das disciplinas do ensino liceal. Diário do Governo, 1936.

PORTUGAL, LISBOA. Decreto $\mathrm{n}^{\circ} .36$ 507, de 17 de setembro de 1947: Promulga a reforma do ensino liceal. Diário do Governo, 1947.

PORTUGAL, LISBOA. Decreto $\mathrm{n}^{\circ} .36$ 508, de 17 de setembro de 1947: Aprova o estatuto do ensino liceal. Diário do Governo, 1947.

PORTUGAL, LISBOA. Decreto ${ }^{\circ} .39$ 807, de 7 de setembro de 1954: Aprova a entrada em vigor a partir do ano escolar seguinte, os programas das disciplinas do ensino liceal. Diário do Governo, 1954.

PORTUGAL, LISBOA. Decreto-lei $n^{\circ} .6 / 2001$, de 18 de janeiro de 2001: Aprova a reorganização curricular do ensino secundário. Diário da Republica, 2001.

PORTUGAL, LISBOA. Decreto-lei n ${ }^{\circ}$. 25/2011 de 29 de dezembro de 2011 (artigo $1^{\circ}$.). Diário da Republica, 2011.

PORTUGAL, LISBOA. Despacho nº. 13: 765/2004 de 13 de julho: Constituição de turmas. Diário da Republica, 2004.

PORTUGAL, LISBOA. Despacho nº 510 G- A/2012 de 12 de abril de 2012: Constituição de turmas. Diário da Republica, 2012.

PORTUGAL. Ministério de Educação. Departamento do Ensino Secundário (2001). Programas de Física e Química A $11^{\circ}$. ano.

RAYMOND, M. \& Negossi Yohannes (2015). O Quinto Compromisso. Lisboa Fundação Francisco Manuel dos Santos, p. 39-41. Disponível em https://www.ffms.pt/upload/docs/ quintocompromisso_JnU1IsWVbUK6Y3OO223rEw.pdf. Acesso em: 28 jun. 2016.

WAISELFISZ, J. J. Tamanho da turma: faz a diferença?. Brasília, DF: MEC, Fundescola, 2000a.

WAISELFISZ, J. J. Tamanho da escola, ambientes escolares e qualidade de ensino. Brasília, DF: MEC, Fundescola, 2000b.

Dados dos Autores

Cesarina Augusto

Universidade de Trás-os-Montes e Alto Douro

csrngst@gmail.com 


\section{José Paulo Cravino}

Universidade de Trás-os-Montes e Alto Douro

Centro de Investigação "Didática e Tecnologia na Formação de Formadores" jcravino@utad.pt

\section{Armando A. Soares}

Universidade de Trás-os-Montes e Alto Douro

Ciener-INEGI/ Universidade do Porto

asoares@utad.pt

\section{J. Bernardino Lopes}

Universidade de Trás-os-Montes e Alto Douro

Centro de Investigação "Didática e Tecnologia na Formação de Formadores"

blopes@utad.pt

Submetido em: 27-12-2016

Aceito em: 2-3-2017 